\title{
Effects of a Conditional Drosophila PKA Mutant on Olfactory Learning and Memory
}

\author{
Willis Li, Tim Tully, ${ }^{1}$ and Daniel Kalderon ${ }^{2}$ \\ Department of Biological Sciences \\ Columbia University \\ New York, New York 10027 \\ ${ }^{1}$ Cold Spring Harbor Laboratory \\ Cold Spring Harbor, New York 11724
}

\begin{abstract}
The requirement for cAMP-dependent protein kinase (PKA) in associative learning of Drosophila was assessed in mutant flies hemizygous for a cold-sensitive allele, $\mathrm{X4}$, of the $D C O$ gene, which encodes the major catalytic subunit of PKA. $D C O^{X 4}$ hemizygotes died as third-instar larvae at $18^{\circ} \mathrm{C}$, the restrictive temperature, but were viable when raised at $25^{\circ} \mathrm{C}$. Shifting adult $D C O^{\mathrm{X} 4}$ hemizygotes from $25^{\circ} \mathrm{C}$ to $18^{\circ} \mathrm{C}$ led to a decrease in PKA activity from $24 \%$ to $16 \%$ of wild-type without impairing viability. At $25^{\circ} \mathrm{C}, D C O^{X 4}$ hemizygotes exhibited reduced initial learning relative to controls but normal memory decay in a Pavlovian olfactory learning assay. Shifting the temperature from $25^{\circ} \mathrm{C}$ to $18^{\circ} \mathrm{C}$ prior to training reduced initial learning to a similar extent in $\mathrm{DCO}^{\mathrm{X} 4}$ hemizygotes and controls but resulted in a steeper memory decay curve only in $D C O^{X 4}$ hemizygotes. These observations are suggestive of a role for PKA in medium-term memory formation in addition to its previously established role in initial learning.
\end{abstract}

\section{Introduction}

A very large number of physiological cellular responses to extracellular signals employ the second messenger, cAMP (Sutherland 1972). The rate of cAMP synthesis, catalyzed by adenylyl cyclase, can be modified via stimulatory (Gs) or inhibitory (Gi) $\mathrm{G}$ proteins that respond to ligand-induced

\footnotetext{
${ }^{2}$ Corresponding author.
}

activation of transmembrane receptors and also by changes in calcium concentration (Gilman 1984; Levitzki 1988; Cooper et al. 1995). Although intracellular cAMP has been shown to interact directly with ion channels in olfactory (Nakamura and Gold 1987; Dhallan et al. 1990) and muscle cells (Delgado et al. 1991), the vast majority of its effects in eukaryotes are mediated by binding to the regulatory subunit $(R)$ of the inactive cAMPdependent protein kinase (PKA) tetramer, $\mathbf{R}_{2} \mathrm{C}_{2}$ (Coffino et al. 1976; Toda et al. 1987; Francis and Corbin 1994). This dissociates monomeric catalytic subunit (C) that can now phosphorylate substrate proteins and thereby alter their activity. PKA is expressed at particularly high levels in the nervous system of mammals (for review, see Walaas and Greengard 1991) and Drosophila (Kalderon and Rubin 1988; Muller and Spatz 1989; Skoulakis et al. 1993), is responsive to a number of neurotransmitters (Uzzan and Dudai 1982; Deutsch and Sun 1992; Saudou et al. 1992; Tatsuno et al. 1992), and can alter the conductance properties of ion channels through phosphorylation (Greengard et al. 1991; Swope et al. 1992; Raymond et al. 1993; Wang et al. 1993). These properties, together with the potential to alter cell shape through phosphorylation of cytoskeleton-associated proteins (Geisler and Weber 1988; Reinhard et al. 1992; Scott et al. 1993) and to alter gene expression by phosphorylation of transcription factors (Gonzalez and Montminy 1989; Rehfuss et al. 1991), make PKA an excellent candidate for mediating short- and long-term changes in synaptic efficiency that underlie learning and memory.

The central importance of cAMP-mediated signal transduction in learning has already been demonstrated in Drosophila melanogaster and in the marine snail, Aplysia californica. In Aplysia, a molecular outline of the actions of cAMP at a defined

LEARNING \& MEMORY 2:320-333 @ 1995 by Cold Spring Harbor Laboratory Press ISSN1072-0502/96 \$5.00

$$
\begin{array}{llllllllllllllll}
\hline & E & A & R & N & I & N & G & \begin{array}{l}
\mathcal{Z} \\
320
\end{array} & M & E & M & O & R & Y
\end{array}
$$


synapse has been developed to account for the sensitization of the gill withdrawal reflex by stimuli to the tail. Enhanced synaptic transmission between sensory and motor neurons is initiated by the modulatory transmitter serotonin (5-HT) that is released when the tail is stimulated. This causes an increase in cAMP concentration in the presynaptic neuron, followed by activation of PKA, closure of (Is) potassium channels, prolonged depolarization, and, hence, enhanced calcium entry and increased release of neurotransmitters (Kandel and Schwartz 1982). Long-term changes in synaptic efficiency are accompanied by changes in synaptic morphology (Bailey and Chen 1988) and have been shown to involve transcriptional induction of several genes mediated by PKA phosphorylation of the transcription factor CREB (Dash et al. 1991; Kaang et al. 1993; Alberini et al. 1994).

In Drosophila, genetic evidence indicates that normal control of cAMP concentration and PKA activity are important for associative learning. Mutations in the dunce ( $d n c)$ gene, a cAMP phosphodiesterase, lead to an increase in basal cAMP levels, whereas mutations in the rutabaga (rut) gene, a calcium/calmodulin-responsive adenylyl cyclase, reduce calcium stimulation of adenylyl cyclase activity without markedly altering basal cAMP concentration. Both mutations disrupt associative and nonassociative learning in a variety of behavioral assays (Byers et al. 1981; Livingstone et al. 1984; Davis and Dauwalder 1991; Tully 1991; Levin et al. 1992). Combining various $d n c$ and rut mutations can restore basal levels of cAMP toward normal but does not restore learning ability when a null mutation of rut, rut ${ }^{l}$, is used (Livingstone et al. 1984; Tully and Quinn 1985; Feany 1990). This is consistent with the idea that modulation of cAMP concentration by the adenylyl cyclase isoform encoded by rut is important for learning, perhaps because it is able to respond to $\mathrm{Ca}^{2+}$ signals as well as to G-protein-mediated activation and thereby respond synergistically to two temporally paired stimuli that converge on a single cell.

Genetic perturbations that alter the response of PKA to CAMP also disrupt associative learning in Drosopbila. Transgenic flies that express inhibitors of PKA or additional PKA catalytic subunit (DCO) under the control of a heat-shock-inducible promoter show marked reductions in learning relative to control flies following a heat shock (Drain et al. 1991). Moreover, enhancer-trapping techniques (Bellen et al. 1989) have been used to isolate a $\mathbf{P}[$ lac $Z]$ transposon insertion in the untrans- lated leader of the $D C O$ gene that reduces PKA activity severalfold. The combination of this insertional mutation, $D C 0^{581}$, and a hypomorphic $D C O$ missense allele, $D C O^{B 10}$, produced viable adult flies of grossly normal morphology that showed reduced Pavlovian olfactory learning (Skoulakis et al. 1993). Furthermore, the expression of lacZ, influenced by the $D C O$ enhancer in $D C O^{581}$, and DC0 protein itself were found to be particularly abundant in the mushroom bodies of the brain, in support of the notion that this may be a key site of action of PKA in the learning process (Davis 1993; Skoulakis et al. 1993; deBelle and Heisenberg 1994).

Several questions regarding the role of Drosopbila PKA in learning warrant further exploration to enhance our mechanistic understanding of learning and memory. One question is whether the effects of PKA perturbations on learning noted above are attributable to developmental defects or acute alterations in physiological responses. This issue is particularly relevant as hypomorphic mutations in the Drosophila PKA catalytic subunit gene $D C O$ are known to affect several developmental processes, whereas null mutations are lethal at larval stages (Lane and Kalderon 1993, 1994; Kalderon 1995). The impaired learning of adults with hypomorphic $D C O$ mutations $\left(D C O^{581} / D C 0^{B 10}\right)$ was assumed to result from acute physiological defects because no obvious morphological changes in brain structure were seen (Skoulakis et al. 1993). More convincingly, learning defects associated with ectopic expression of $D C O$ and PKA inhibitors were manifest immediately following heat shock-induced expression (Drain et al. 1991). These measurements were, however, made against a background of substantially impaired learning owing to the heat shock treatment itself.

A second question is whether PKA is required for all measurable facets of learning and memory in Drosophila. Loss-of-function DCO mutations that reduce PKA activity to $20 \%$ of wild type show severe reductions in initial learning but no apparent reduction in memory for $3 \mathrm{hr}$ after training (Skoulakis et al. 1993). Similarly, ectopic expression of PKA inhibitors reduced initial learning but did not appear to accelerate memory decay (Drain et al. 1991), though in this case the effects of the inhibitors could not be resolved completely from the effects of heat shock and the temporal decay of the transiently expressed inhibitors to give a complete time course of memory retention.

A third question is whether different aspects

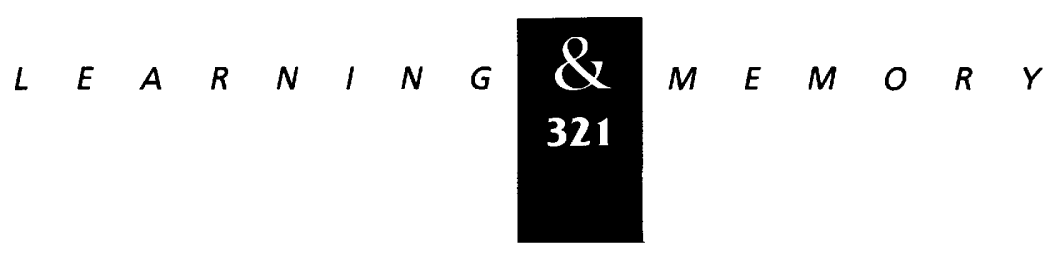


of learning and memory require different thresholds of PKA activity. This might be expected if PKA participated in distinct learning processes by phosphorylation of different substrates. The only quantitative data correlating PKA activity and learning suggest a threshold somewhere between $60 \%$ and $20 \%$ of wild-type PKA activity for discerning any pronounced effects on learning (Skoulakis et al. 1993). The effects of reducing PKA activity below $20 \%$ remain to be explored.

We sought to identify conditional alleles of $D C O$ to demonstrate acute requirements for PKA in learning and to investigate the effects of reducing activity to minimal levels on both initial learning and memory. Here, we report on the isolation of cold-sensitive alleles of $D C O$ and the use of one of them in assays of associative learning. Initial studies using a courtship conditioning assay (Siegel and Hall 1979; Griffith et al. 1993) suggested that temperature-dependent reductions in PKA activity were associated with reduced memory over a 3-hr retention period without affecting initial learning ( $\mathrm{Li}$ 1995). However, the statistical significance of these results was hard to assess because performance indices were not normally distributed. We therefore used the same cold-sensitive PKA mutant in a Pavlovian olfactory assay of learning and report the results here. Flies raised with reduced PKA activity ( $24 \%$ of wild type) were deficient in initial learning but exhibited memory decay rates similar to controls. Further reduction of PKA activity (to $16 \%$ of wild type) in adult flies produced little change in initial learning but was associated with an increased memory decay rate. These results suggest, for the first time, that there may be an acute physiological requirement for PKA in medium-term memory (MTM) in addition to its established role in initial learning.

\section{Materials and Methods}

\section{ISOLATION OF COLD-SENSITIVE MUTANTS}

Male flies of genotype $S 6 \mathrm{cnbw} ; \mathrm{y}^{506}$ (S6 represents a $\mathrm{P}\left[r y^{+}\right]$insertion at $30 \mathrm{C}, 1$ map unit from the $D C O$ locus) were fed with $25 \mathrm{~mm}$ ethylmethanesulfonate (EMS) and mated to $b w ; r y^{506}$ virgin females (as in Grigliatti 1986). $\mathrm{F}_{1}$ males were singly mated to $D C O^{H 2} S 6 c n b w / C y O ; r y^{506}$ $\left(D C O^{H 2}\right.$ is a strong $D C O$ allele) virgin females at $18^{\circ} \mathrm{C}$ and at $29^{\circ} \mathrm{C}$. The absence of white-eyed progeny of genotype [S6cnbw] ${ }^{*} / D C O^{H 2} S 6 \mathrm{cnbw}$ indicates a second chromosome carrying a mutation that is lethal over $\mathrm{DCO}^{\mathrm{H}}$. These chromosomes were converted to balanced stocks and retested at $18^{\circ} \mathrm{C}, 25^{\circ} \mathrm{C}$, and $29^{\circ} \mathrm{C}$ for viability over $D f(2 L) \gamma 15$ (which lacks the $D C O$ gene) and several of the previously isolated $D C O$ alleles (Lane and Kalderon 1993). To map the lethal mutation, $[S \sigma c n b w]^{*} / C y O ; r y^{506}$ flies were crossed to $r y^{506}$ flies. $\mathrm{F}_{1}$ virgin females of genotype $[S \sigma \mathrm{cnbw}]^{*} /+$; $r y / r y$ were mated to $D f(2 L) \gamma 15 / C y O ; r y^{506}$ and progeny flies were scored for $\mathrm{ry}^{+}$and $\mathrm{CyO}$ markers. In all cases, the lethal mutation mapped within 4 map units of the $\mathrm{P}\left[r y^{+}\right]$insertion, consistent with the map distance of 1.0 map unit obtained for previously isolated mutations shown to be $D C O$ alleles by DNA sequence determination.

\section{KINASE ASSAYS}

Kinase assays were carried out as described previously using adult males at 2-5 days posteclosion (Lane and Kalderon 1993). Five time points in a 1-min reaction were taken to calculate the reaction rates. PKA activity in fly extracts from the mutants was always compared in the same experiment with that of $D f(2 L) \gamma 15 / C y O$ flies, which have $50 \%$ of wild-type PKA activity. Each extract was assayed twice, and several extracts were made for each genotype and temperature condition. Total protein concentration of extracts, assayed as in Bradford (1976), were very similar in all assays and were used to calculate specific PKA activities.

\section{FLY CULTURE AND MAINTENANCE}

Male flies of genotype $D C 0^{X 4} S 6 \mathrm{cnbw} /$ $D f(2 L) \gamma 15$ were generated by crossing $D C O^{X 4}$ S6 cnbw/CyO; $y^{506}$ males to $D f(2 L) \gamma 15 /$ $\mathrm{CyO} ; \boldsymbol{r y}^{506}$ virgin females. Control flies of genotype $S 6 \mathrm{cnbw} / \mathrm{CyO} ; \mathrm{ry}^{506}$ were generated by crossing $S 6 \mathrm{cnbw}$; $\mathrm{ry}^{506}$ males to the same virgin females, $D f(2 L) \gamma 15 / C y O ; r y^{506}$. Flies were grown on the standard sugar-cormeal-agar medium (Boynton and Tully 1992) and kept at $25^{\circ} \mathrm{C}$, except for tests at the restrictive temperature, $18^{\circ} \mathrm{C}$.

\section{PAVLOVIAN OLFACTORY LEARNING}

Flies were trained and tested with the odorshock conditioning procedure of Tully and Quinn (1985) with modifications described in Tully et al. (1994). About 100 1- to 4-day-old flies of either $D C O^{X} S 6 \mathrm{cn} b w / D f(2 L) \gamma 15$ (mutant) or $S 6 \mathrm{cn} \mathrm{bw/}$

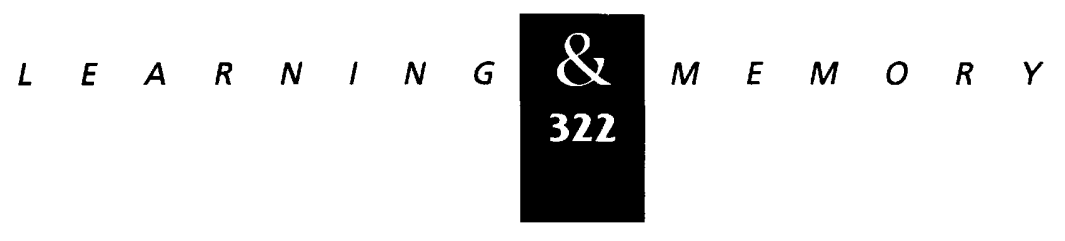


$D f(2 L) \gamma 15$ (control) genotype were used in each trial. Flies of each genotype were trained simultaneously in two training machines set in parallel, with each genotype receiving an equal number of trainings in each machine to avoid bias. After each training, flies were either tested immediately ( 0 min time point; initial learning) or removed from the training chamber and stored in food vials in the dark for $10,20,30,60$, or 180 min before they were tested. Performance index (PI) was calculated as described in Boynton and Tully (1992).

\section{OLFACTORY ACUITY AND SHOCK REACTIVITY}

Olfactory acuity was assessed as described in Tully et al. (1994) with two different odor concentrations, one normally used in training and the other at 100 -fold dilution, at either $25^{\circ} \mathrm{C}$ or $18^{\circ} \mathrm{C}$ for each genotype. The ability of flies of different genotypes to avoid electrical shocks at $60 \mathrm{~V}$ (normally used in training) and $20 \mathrm{~V}$ was tested as described (Luo et al. 1992) at both $25^{\circ} \mathrm{C}$ and $18^{\circ} \mathrm{C}$.

\section{STATISTICAL ANALYSES OF BEHAVIORAL DATA}

PIs are distributed normally (Tully and Gold 1993); so untransformed data were analyzed parametrically with the Macintosh software package JMP 3.1 (SAS Institute, Inc.). All pairwise comparisons were planned. To maintain an experimentwise error rate of $a=0.05$, the critical $P$ values were adjusted accordingly (Sokal and Rohlf 1981) and are listed below for each experiment. All behavioral experiments were performed in a balanced fashion, with $N=2$ PIs collected per day per group (genotype \pm temperature shift). In these experiments, the experimenter was blind to genotype.

LEARNING AND MEMORY IN WILD-TYPE [S6/Df( $2 L) \gamma 15]$ AND MUTANT $\left[D C O^{X 4} / D f(2 L) \gamma 15\right]$ FLIES AT PERMISSIVE $\left(25^{\circ} \mathrm{C}\right)$ AND RESTRICTIVE $\left(18^{\circ} \mathrm{C}\right)$ TEMPERATURES

PIs from two GENOtypes [S6/Df(2L) $\gamma 15]$ and $\left.\left.D C O^{X 4} / D f(2 L) \gamma 15\right]\right)$, two TEMPeratures $\left(25^{\circ} \mathrm{C}\right.$ and $\left.18^{\circ} \mathrm{C}\right)$, and six retention TIMEs $(0,10,20,30,60$, and $180 \mathrm{~min}$ ) were subjected to a three-way ANOVA with GENO $[F(1,120)=216.29$, $P<0.001]$, TEMP $[F(1,120)=151.16, P<0.001]$, and TIME $[F(1,120)=58.58, P<0.001]$ as main effects and GENO $\times$ TEMP $[F(1,120)=0.023, P=$
$0.872]$, GENO $\times$ TIME $[F(5,120)=1.64, P=0.154]$ and TEMP $\times$ TIME $[F(5,120)=0.2 .24, P=0.055]$ as two-way interaction terms and GENO $\times$ TEMP $\times$ $\operatorname{TIME}[F(5,120)=0.84, P=0.523]$ as the three-way interaction term (Fig. 4A,B, below). The 12 planned comparisons were deemed significant if $P<0.004$ and are summarized in the legend to Fig. ure 4 , below.

LEARNING/MEMORY OF MUTANTS EXPRESSED AS A PROPORTION OF WILD-TYPE FLIES (PI RATIO) AT PERMISSIVE $\left(25^{\circ} \mathrm{C}\right)$ AND RESTRICTIVE $\left(18^{\circ} \mathrm{C}\right)$ TEMPERATURES

Any difference in learning between mutant flies at permissive and restrictive temperatures can result from a specific effect of temperature on PKA activity encoded by the cold-sensitive $X 4$ allele or from a nonspecific effect of temperature that is common to flies of all genotypes. To eliminate the latter, nonspecific effect of temperature, we divided the PI of mutant flies by the PI of control flies for each assay time at each temperature (Fig. 4C, below). Means + S.E.M.s of PIs for each of the groups represented in Figure 4, $A$ and B, below, were used to calculate "PI Ratios." At each temperature $\left(25^{\circ} \mathrm{C}\right.$ or $\left.18^{\circ} \mathrm{C}\right)$, the PI Ratio $_{\mathrm{i}}=\left(\right.$ mean $\mathrm{X} 4_{\mathrm{i}} /$ mean $\left.\mathrm{S} 6_{\mathrm{i}}\right) \times\left(1+\left[\right.\right.$ [s.E.M. ${ }^{2} /($ mean $\left.\left.S 6_{i}\right)^{2}\right]$ ), where PI Ratio ${ }_{i}=$ the mean PI of mutant flies at retention time $i(0,10,20,30,60$, or 180 min) expressed as a proportion of the corresponding mean PI of wild-type flies, mean $\mathrm{X} 4=$ the mean PI of $D C O^{X /} / D f(2 L) \gamma 15$ mutants, mean $\mathrm{S} 6=$ the mean PI of $S 6 / D f(2 L) \gamma 15$ wild-type flies, and S.E.M. $=$ the average S.E.M. of the groups in Figure 4, $A$ and $B$, as determined from a one-way ANOVA on PIs (this value was determined as the square root of the "mean square error" divided by the average within-group sample size). Because this ratio was determined from two mean values, each of which have an associated s.E.M., then S.E.M..PI RATIO $=\left(\left[(\text { mean X } 4)^{2} /(\text { mean S6 })^{2}\right] \times\left[\right.\right.$ s.E.M. ${ }^{2} /($ mean X4 $)^{2}+$ S.E.M. $\left.{ }^{2} /(\text { mean S6 })^{2}\right]^{1 / 2}$.

This calculation of the S.E.M. of a ratio of two s.E.M.s is derived from Tully and Hirsch (1982), where S.E.M. ${ }^{2}$ provides an estimate of the variance of group mean PIs. The retention curves of PI Ratios for $25^{\circ} \mathrm{C}$ and $18^{\circ} \mathrm{C}$ are plotted as the upper two lines of Figure 4C, below. PI Ratios, S.E.M.s, and associated degrees of freedom for each group then were subjected to a one-way ANOVA with GROUP $[F(11,84)=4.84, P<0.001]$ as the main effect. The

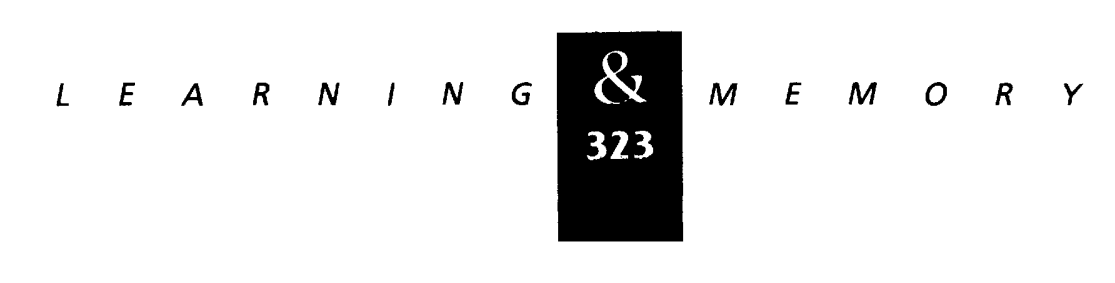


Li et al.

six subsequent planned comparisons were deemed significant if $\mathrm{P} \leqslant 0.009$ and are summarized in the legend to Figure 4, below. These planned comparisons represent the differences between PI Ratios at $25^{\circ} \mathrm{C}$ vs. $18^{\circ} \mathrm{C}$ and are plotted, along with their corresponding SEMs, as the lower line in Figure $4 \mathrm{C}$, below.

OLFACTORY ACUTTY IN WIDE-TYPE AND MUTANT FLIES AT PERMISSIVE AND RESTRICTIVE TEMPERATURES

PIs from two GENOtypes [S6/Df(2L) $\gamma 15$ and $\left.D C O^{X 4} / D f(2 L) \gamma 15\right)$, four ODOR/concentration groups (OCT $10^{-2}$; OCT $10^{\circ}$; $\mathrm{MCH} 10^{-2}$; or $\left.\mathrm{MCH} 10^{\circ}\right)$, and two TEMPeratures $\left(25^{\circ} \mathrm{C}\right.$ and $18^{\circ} \mathrm{C}$ ) were subjected to a three-way ANOVA with GENOtype $[F(1,112)=0.05, \quad P=0.82], \quad$ with ODOR $[F(3,112)=95.11, P<0.001]$ and TEMP $[F(1,112)=2.61, P=0.11]$ as main effects; with GENO $\times$ ODOR $[F(3,112)=0.17, P=0.92]$, GENO $\times$ TEMP $[F(1,112)=0.47, P=0.49]$, and ODOR $\times$ $\operatorname{TEMP}[F(3,112)=0.02, P=0.99]$ as two-way interaction terms; and with GENO $\times$ ODOR $\times$ TEMP $[F(3,112)=0.30, P=0.83]$ as the three-way interaction term (Fig. 5A, below).

SHOCK REACTIVITY IN WILD-TYPE AND MUTANT FLIES AT PERMISSIVE AND RESTRICTIVE TEMPERATURES

PIs from two GENOtypes [S6/Df(2L) $\gamma 15$ and $\left.D C 0^{X 4} / D f(2 L) \gamma 15\right]$, two VOLTages $(20 \mathrm{~V}$ or $60 \mathrm{~V})$, and two TEMPeratures $\left(25^{\circ} \mathrm{C}\right.$ and $\left.18^{\circ} \mathrm{C}\right)$ were subjected to a three-way ANOVA with GENO $[F(1,40)=0.08, \quad P=0.78], \quad$ VOLT $\quad[F(1,40)=$ 153.83, $P<0.001]$, and TEMP $[F(1,40)=0.44$, $P=0.51]$ as main effects; with GENO $\times$ VOLT $[F(1,40)=0.07, P=0.80]$, GENO $\times$ TEMP $[F(1,40)=$ $0.13, P=0.72]$ and VOLT $\times$ TEMP $[F(1,40)=0.24$, $P=0.62]$ as two-way interaction terms; and with GENO $\times$ VOLT $\times$ TEMP $[F(1,40)=0.11, P=0.74]$ as the three-way interaction term (Fig. 5B, below).

COMPARISONS OF RELATIVE LEARNING/MEMORY (PI RATIO) AT PERMISSIVE $\left(25^{\circ} \mathrm{C}\right)$ AND RESTRICTIVE $\left(18^{\circ} \mathrm{C}\right)$ TEMPERATURE

The PI ratios for $D C O^{X 4} / D f(2 L) \gamma 15$ mutants at $25^{\circ} \mathrm{C}$ and $18^{\circ} \mathrm{C}$ in Figure $4 \mathrm{C}$, below, were plotted along with similar PI Ratios calculated as above using the data from Tully and Quinn (1985) for amnesiac (amn) mutants, deficient for MTM (Tully et al. 1990), and wild-type (Canton-S) flies. This set of PI Ratios, S.E.M.S, and associated degrees of freedom then were subjected to a one-way
ANOVA with GENO $[F(2,226)=4.23, P=0.016]$ as the main effect. The two subsequent planned comparisons were deemed significant if $P \leqslant 0.025$ and are summarized in the legend to Figure 6, below.

\section{Results}

\section{ISOLATION OF COLD-SENSITIVE ALLELES OF $D C O$}

Ten EMS-induced alleles of $D C O$ have been isolated previously as recessive lethals by testcrossing to the null $D C O$ deficiency, $D f(2 L) \gamma 15$, at $25^{\circ} \mathrm{C}$ (Lane and Kalderon 1993). None of these original alleles complemented $D f(2 L) \gamma 15$ for viability at $18^{\circ} \mathrm{C}$ or $29^{\circ} \mathrm{C}$, although the weakest alleles (B10, B12, D30) showed a mild cold-sensitive phenotype, partially complementing each other at $25^{\circ} \mathrm{C}$ but not at $18^{\circ} \mathrm{C}$ (Lane and Kalderon 1993). To isolate more strictly conditional $D C O$ alleles, we screened for EMS-induced mutations that were lethal in combination with the strong $D C O$ allele, $D C O^{H 2}$ at either $18^{\circ} \mathrm{C}$ or $29^{\circ} \mathrm{C}$ (see Materials and Methods). The lethality of all 32 newly isolated mutations, including $D C O^{T 4}$ and $D C O^{X 4}$, and of the previously isolated and sequenced $D C O$ alleles was found by recombination to map within 4 map units of a $\mathrm{P}\left[r y^{+}\right]$insertion at 30C. This indicates that all of the newly induced mutations are likely to be alleles of $D C O$.

All 32 new $D C O$ alleles were tested for complementation of the $D C O$ deficiency, $D f(2 L) \gamma 15$ at $18^{\circ} \mathrm{C}, 25^{\circ} \mathrm{C}$, and $29^{\circ} \mathrm{C}$ and for complementation of selected hypomorphic $D C O$ alleles at $18^{\circ} \mathrm{C}$ and $25^{\circ} \mathrm{C}$. Only $2, D C O^{T 4}$ and $D C O^{X 4}$, of the 32 mutations showed pronounced temperature-dependent complementation properties. Both $D C O^{T 4}$ and $D C O^{X 4}$ mutations showed no complementation of $D f(2 L) \gamma 15$ at $18^{\circ} \mathrm{C}$ but almost full complementation for viability at $25^{\circ} \mathrm{C}$ (Fig. 1). These alleles clearly encode some PKA activity at $18^{\circ} \mathrm{C}$ as they were able to complement the three weak alleles, $D C O^{B 1 O}, D C O^{B 12}$, and $D C O^{D 30}$, at this temperature. Also the majority of $D C O^{\mathrm{X} 4}$ and $D C O^{T 4}$ hemizygotes died as third-instar larvae at $18^{\circ} \mathrm{C}$, characteristic of weak $D C O$ alleles. Animals that are zygotically null for $D C O$ die as first-instar larvae (Lane and Kalderon 1993).

\section{BIOCHEMICAL PROPERTIES OF COLD-SENSITIVE ALLELES $T 4$ AND $X 4$}

The effects of $D C O^{T 4}$ and $D C O^{X 4}$ mutations on PKA activity were measured to verify that these

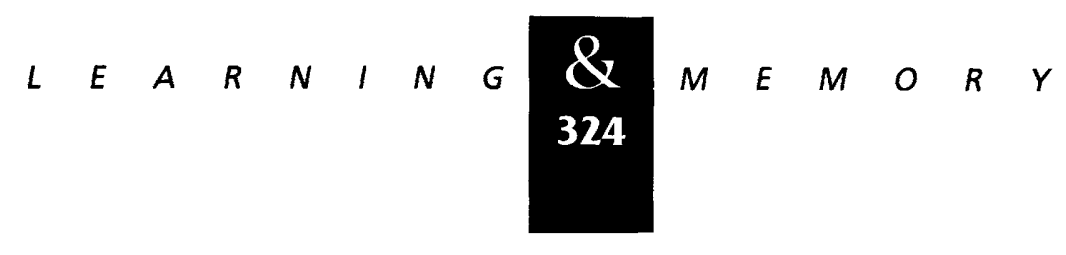




\begin{tabular}{|c|c|c|c|c|}
\hline $\begin{array}{l}\text { DC0 } \\
\text { allele }\end{array}$ & \multicolumn{2}{|c|}{$\begin{array}{c}\text { DC0 } \\
\text { \% VIABILITY }\end{array}$} & \multicolumn{2}{|c|}{ \% VIA ${ }^{\text {X4 }}$} \\
\hline $\operatorname{Df}(2 \mathrm{~L}) \gamma 15$ & 0 & 91 & 0 & 57 \\
\hline B3 & 4 & 56 & 1 & 71 \\
\hline $\mathrm{H} 2$ & 8 & 66 & 1 & 44 \\
\hline G9 & 3 & 58 & 1 & 44 \\
\hline C4 & 6 & 80 & 1 & 65 \\
\hline $\mathrm{A} 13$ & 10 & 50 & 3 & 68 \\
\hline H3 & 16 & 61 & 21 & 66 \\
\hline B12 & 56 & ND & 53 & 69 \\
\hline D30 & 86 & ND & 80 & 87 \\
\hline B 10 & 108 & 92 & 94 & 92 \\
\hline
\end{tabular}

Figure 1: Complementation properties of cold-sensitive alleles, $D C 0^{X 4}$ and $D C 0^{T 4}$. The viability of various allelic combinations was determined by counting adult progeny from a cross between five pairs of heterozygotes (over $\mathrm{CyO}$ ) in a vial. The tabulated percentage viability was calculated as the number of non-CyO progeny divided by the number of $\mathrm{CyO}$ progeny and multiplied by 50. (ND) not determined. The figures given are averages of many such experiments. The DCO alleles used, other than $\mathrm{T} 4$ and $\mathrm{X} 4$, have been described previously and are written from top to bottom in descending order of allelic strength (Lane and Kalderon 1993).

mutations affect the $D C O$ gene and to investigate the severity of PKA dysfunction at $25^{\circ} \mathrm{C}$ and $18^{\circ} \mathrm{C}$. It has been shown previously that there is a close correlation between $\mathrm{DCO}$ gene activity and the PKA activity measured in adult fly extracts in the presence of saturating amounts of cAMP (Lane and Kalderon 1993). Thus, adult flies that are het- erozygous for a strong $D C O$ allele or the deficiency, $D f(2 L) \gamma 15$, have only $50 \%$ of wild-type PKA activity. Extracts of $D C O^{X 4} / D f(2 L) \gamma 15$ adults showed large reductions in PKA activity relative to $D f(2 L) \gamma 15 / C y O$ control flies that were raised in parallel under identical conditions (Fig. 2). At $25^{\circ} \mathrm{C}, D C O^{\mathrm{X}} / D f(2 L) \gamma 15$ flies had $24 \%$ of wildtype PKA activity. When these flies were shifted to $18^{\circ} \mathrm{C}$, the kinase activity was further reduced to only $16 \%$ of the wild-type level. The same reduced level of PKA activity (16\%) was measured at both 3 and $16 \mathrm{hr}$ after shifting adult flies from $25^{\circ} \mathrm{C}$ to $18^{\circ} \mathrm{C}$ (Fig. 2). The change in PKA activity, from $24 \%$ to $16 \%$ in $D C O^{X 4}$ hemizygotes, is consistent with measurements on flies carrying other $D C O$ alleles that establish a level of $\sim 15 \%-20 \%$ as a threshold required for viability in Drosopbila (W. $\mathrm{Li}$ and D. Kalderon, unpubl.). These results therefore support the idea that $D C O^{X 4}$ is a cold-sensitive allele of $D C O$ and that in vitro measurements of PKA activity reflect the change in activity of $D C O^{X 4}$-encoded enzyme in vivo. Similar measurements indicated that the PKA activity in $D C O^{T 4} /$ $D f(2 L) \gamma 15$ flies drops from $36 \%$ to $18 \%$ of wildtype upon shifting adult flies from $25^{\circ} \mathrm{C}$ to $18^{\circ} \mathrm{C}$.

Quantitation of p40 DC0 protein concentration in $D C O^{X 4}$ homozygous flies by Western blot indicated an approximately twofold reduction in protein levels relative to wild-type at $25^{\circ} \mathrm{C}$ but was not sufficiently accurate to determine if this fully accounts for the reduced kinase activity of $D C O^{X 4}$ homozygotes (Fig. 3). Also, it was not possible to establish whether shifting from $25^{\circ} \mathrm{C}$ to $18^{\circ} \mathrm{C}$ reduced the concentration of $D C O^{X 4}$ protein further.

\begin{tabular}{|c|c|c|c|c|c|c|c|c|c|c|}
\hline \multirow{2}{*}{$\begin{array}{c}\text { Genotype } \\
\text { Temperature } \\
\left({ }^{\circ}\right)\end{array}$} & \multicolumn{2}{|c|}{$\frac{S 6 c n b w}{\text { S6cnbw }}$} & \multicolumn{2}{|c|}{$\frac{D C 0^{\mathrm{X} 4} S 6 c n b w}{D C 0^{\mathrm{X} 4} S 6 c n b w}$} & \multicolumn{2}{|c|}{$\frac{D C 0^{\mathrm{X}^{4}}{ }^{4} 6 c n b w}{D f(2 L) \gamma 15}$} & \multicolumn{2}{|c|}{$\frac{D C O^{\mathrm{T} 4} S 6 \mathrm{cnbw}}{D f(2 L) \gamma 15}$} & \multicolumn{2}{|c|}{$\frac{D f(2 L) \gamma 15}{C y O}$} \\
\hline & 25 & 18 & 25 & 18 & 25 & 18 & 25 & 18 & 25 & 18 \\
\hline $\begin{array}{c}\text { \% kinase } \\
\text { activity }\end{array}$ & 104 & 98 & 38 & 21 & 24 & 16 & 36 & 18 & 50 & 50 \\
\hline $\begin{array}{c}\text { \# of } \\
\text { Assays }\end{array}$ & 2 & 2 & 2 & 4 & 2 & 4 & 4 & 4 & N.A. & N.A. \\
\hline $\begin{array}{c}\text { Standard } \\
\text { Error of Mean }\end{array}$ & 4 & 3 & 3 & 4 & 3 & 2 & 2 & 2 & N.A. & N.A. \\
\hline
\end{tabular}

Figure 2: PKA activities encoded by $D C 0^{X 4}$ and $D C 0^{T 4}$. PKA activities of extracts were calculated as the rate of Kemptide phosphorylation in the presence of $10 \mu \mathrm{M}$ CAMP (see Materials and Methods). Df(2L) $y 15 / C y O$ [rather than S6cnbw/ $D f(2 L) \gamma 15]$ flies were used as convenient controls in all assays because the wild-type DCO gene on CyO and S6cnbw chromosomes encodes equivalent activities; $\mathrm{Df}(2 \mathrm{~L}) \gamma 15 / \mathrm{CyO}$ flies are assumed to encode $50 \%$ of wild-type activity, as shown previously (Lane and Kalderon 1993). All other activities are expressed relative to that of $D f(2 \mathrm{~L}) \gamma 15 / \mathrm{CyO}$ measured in the same experiment. The activities for $D C 0^{x 4}$ flies at $18^{\circ} \mathrm{C}$ were measured after shifting flies to $18^{\circ} \mathrm{C}$ for $2-3 \mathrm{hr}(15.8 \%)$ or $\sim 12-16 \mathrm{hr}(16.4 \%)$. As the results were very similar, the average of the two is tabulated. (N.A.) Not applicable.

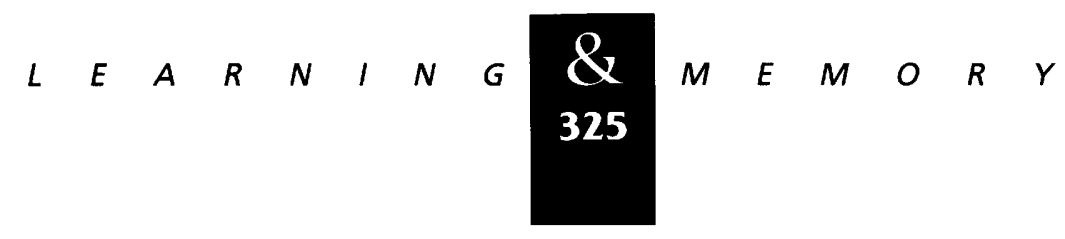



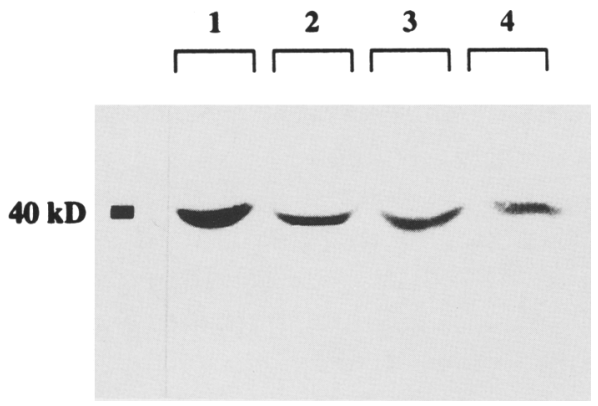

Figure 3: Western blot of Drosophila Extracts. The protein concentrations in homogenates of adult flies were measured (Bradford 1976) so that the same amount of total protein was loaded in each lane for SDS-PAGE. After transfer to nitrocellulose, DCO p40 antigen was detected using a primary DCO antibody purified as described previously (Lane and Kalderon 1993) and alkaline-phosphatase-conjugated second antibody. Extracts of control, S6cnbw homozygotes (lane 1) have considerably more DC0 protein than Df(2L) $\gamma 15 / C y O$ flies (lane $2)$, which are expected to have $50 \%$ of wild-type levels, and $D C 0^{x 4} S 6 c n b w$ homozygotes at $25^{\circ} \mathrm{C}$ (lane 3) and $18^{\circ} \mathrm{C}$ (lane 4 ). This experiment was repeated several times using different amounts of extract. In each case, $D C O^{X 4}$ homozygotes showed less protein than wild type and similar levels to $D f(2 L) \gamma 15 / C y O$ flies, as in the example shown.

\section{EFFECTS OF PKA MUTATIONS ON PAVLOVIAN OLFACTORY LEARNING}

We measured initial learning and memory retention after one training session of flies with various reductions in PKA activity using a Pavlovian odor avoidance assay (Tully and Quinn 1985; Tully et al. 1994). The control flies used in these experiments were heterozygous for the $D C O$ deficiency, $D f(2 L) \gamma 15$, and $S 6 c n b w$, the parent chromosome of $D C O^{X 4}$. These flies have $50 \%$ of normal PKA activity and were therefore not expected to show marked defects in learning (cf. Skoulakis et al. 1993). At $25^{\circ} \mathrm{C}$ the control flies showed robust initial learning that decayed roughly exponentially over a 3-hr period to an apparent asymptote in excess of $50 \%$ of the initial learning score (Fig. 4A), as described previously for wild-type flies (Tully and Quinn 1985; Tully et al. 1990; Boynton and Tully 1992; Dura et al. 1993; Tully and Gold 1993). At $18^{\circ} \mathrm{C}$, control flies showed a similar time course of memory retention but all learning scores were reduced by $\sim 25 \%$ relative to the values at $25^{\circ} \mathrm{C}$ (Fig. 4B).

A three-way ANOVA of the combined data summarized in Figure $4, A$ and $B$, revealed a significant effect of GENOtype $(P<0.001)$, a signifi-
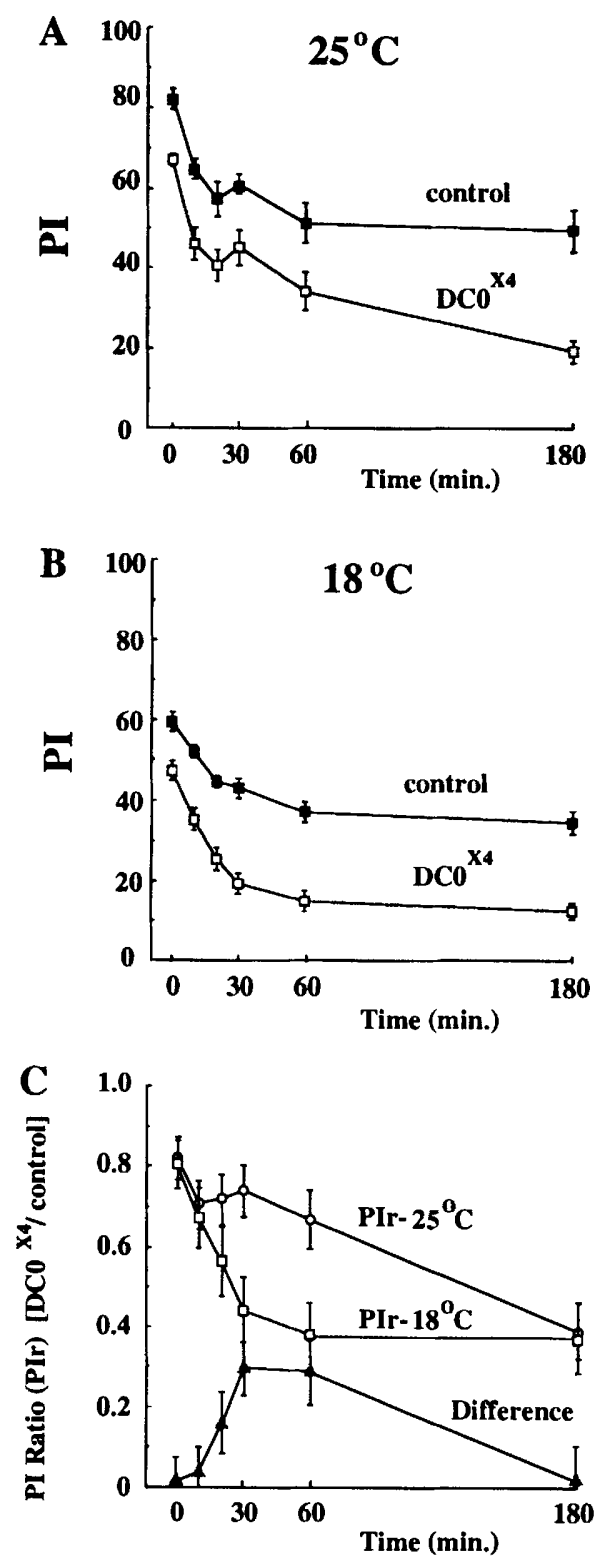

Figure 4: Pavlovian olfactory learning and memory of PKA mutants. DCO ${ }^{x 4} / D f(2 L) \gamma 15$ ( $\square$; lower curve) and control, S6/Df(2L) $\gamma 15$ flies ( $\boldsymbol{\square}$; upper curve) were assayed for classical odor-shock conditioning at two different temperatures, $25^{\circ} \mathrm{C}(A)$ and $18^{\circ} \mathrm{C}(B)$. Performance indices (Pls) are plotted against time intervals between training and testing. Error bars represent S.E.M.; mean Pls $(n=6)$ for each genotype and time points $(0,10,20,30$, $60,180 \mathrm{~min}$ ) are shown. (C) PI ratios of $D C 0^{x 4}$ hemizygotes relative to controls at each memory retention point at $25^{\circ} \mathrm{C}(\bigcirc)$ and $18^{\circ} \mathrm{C}(\square)$ are plotted. ( $\left.\mathbf{\Delta}\right)$ The difference between $\mathrm{PI}$ ratios at the two temperatures. $\mathrm{PI}$ ratios and S.E.M.S are calculated as described in Materials and Methods.

$$
\text { ….... 娄 }
$$


cant effect of TEMPerature $(P<0.001)$, and a significant effect of retention TIME $(P<0.001)$ but no significant interactions among these experimental variables (all $P s>0.05$ ). Thus, the performance of mutant $D C O^{X 4}$ hemizygotes was subnormal at all retention times, and temperature lowered performance similarly in mutant and control flies.

In the above analysis of performance differences, a specific effect of temperature shift on mutant $D C O^{X^{4}}$ hemizygotes would be detected in the GENO $\times$ TEMP and/or GENO $\times$ TEMP $\times$ TIME interactions terms. However, this type of statistical analysis has notoriously low power for detecting even moderately large effects (Wahlsten 1990). Consequently, we have also analyzed the temperature-shift effects that are specific to mutant $D C O^{X 4}$ hemizygotes by expressing mutant mean PIs as a proportion of the corresponding control mean PIs to produce a PI Ratio for each time and temperature (Fig. 4C; see Materials and Methods). This treatment of the data revealed that reducing PKA activity from $24 \%$ to $16 \%$ of wild type in adult flies had no effect on initial learning but led to a more rapid decay of memory in the first hour following training. The difference between the memory curves of flies with $24 \%$ and $16 \%$ PKA activity peaked at $30 \mathrm{~min}(P=0.008)$ and then decreased again to zero by $180 \mathrm{~min}$ after training (Fig. 4C).

The nonspecific and allele-specific effects of temperature shift on performance in the Pavlovian learning assay were not attributable to changes in task-relevant sensorimotor responses, because experimental and control flies behaved similarly in tests of olfactory acuity and shock reactivity at both $18^{\circ} \mathrm{C}$ and $25^{\circ} \mathrm{C}$ (Fig. $5 \mathrm{~A}, \mathrm{~B}$; see Materials and Methods).

These data suggest that the reduction in PKA activity owing to temperature shift of adult mutant $D C O^{X f}$ hemizygotes disrupted the normal function of MTM (see Discussion). Previous behavior-genetic studies also suggested the involvement of amn mutants in MTM (Tully et al. 1994). Thus, we expressed the amn memory retention data from Tully and Quinn (1985) as PI Ratios (using wildtype Canton-S flies as controls) and plotted the resulting memory curve for $a m n$ along with those for mutant $D C O^{X 4}$ hemizygotes assayed at $18^{\circ} \mathrm{C}$ or $25^{\circ} \mathrm{C}$ (Fig. 6). Visual inspection and statistical analysis reveals a striking similarity between the memory curves of amn mutants assayed at $25^{\circ} \mathrm{C}$ and $D C O^{X 4}$ mutants assayed at $18^{\circ} \mathrm{C}(P=0.451)$, in contrast to the improved performance of $D C 0^{X 4}$ mutants assayed at $25^{\circ} \mathrm{C}(P=0.024)$.

\section{Discussion}

We have investigated the role of PKA in associative learning in Drosophila using a conditional

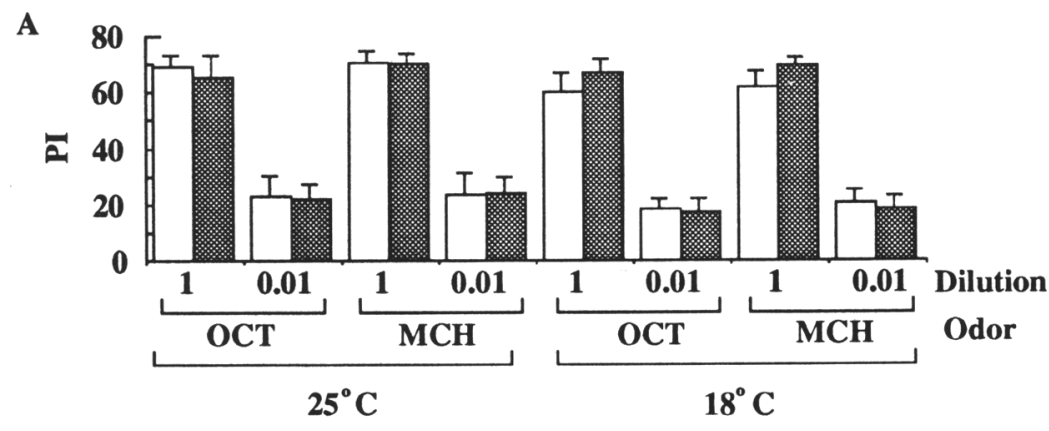

B

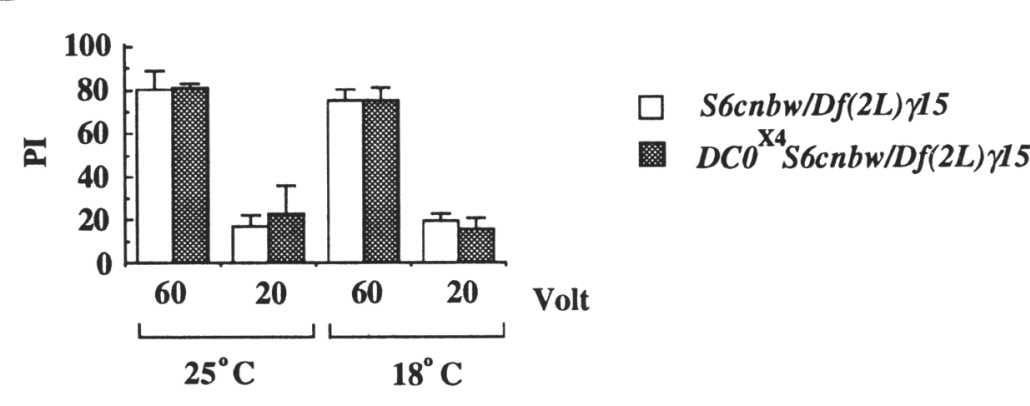

Figure 5: Task-relevant sensorimotor behaviors are normal in mutant flies. $(A)$ Olfactory acuity and $(B)$ shock reactivity of $D C O^{X_{4}}$ hemizygous flies (shaded bars) vs. control (open bars) flies were tested at $25^{\circ} \mathrm{C}$ and $18^{\circ} \mathrm{C}$, respectively. Mean PIs $(n=8)$ are shown with S.E.M. No significant differences were detected between the two genotypes at either temperature.

$$
\text { ……" }
$$




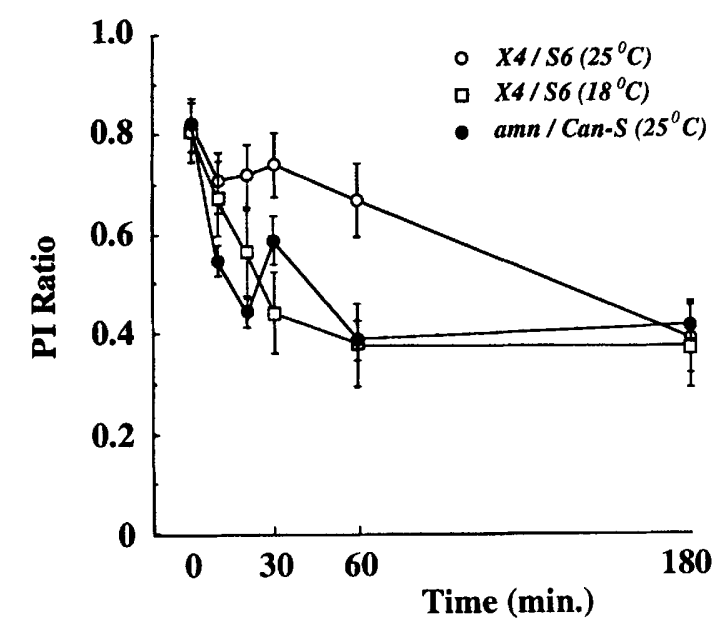

Figure 6: The temperature-shift-specific effect of $D C 0^{X 4}$ disrupts MTM. Comparison of PI ratios of $D C 0^{x_{4}}$ hemizygotes at $18^{\circ} \mathrm{C}$ or $25^{\circ} \mathrm{C}$ with amn flies at $25^{\circ} \mathrm{C}$. The $\mathrm{PI}$ ratios of $D C 0^{X 4}$ hemizygotes at $18^{\circ} \mathrm{C}(\square)$ or $25^{\circ} \mathrm{C}(\mathrm{O})$ are plotted with those of amn mutants (O) recalculated from the data of Tully and Quinn 1985). Note the PI Ratios for $D C 0^{x 4}$ hemizygotes at $18^{\circ} \mathrm{C}$ decay at a similar rate to those for amn mutants, and both decay rates are faster than that for $D C 0^{X 4}$ hemizygotes at $25^{\circ} \mathrm{C}$. PI ratios of $\mathrm{DCO}^{\mathrm{X}}$ hemizygotes are the same as shown in Fig. $4 \mathrm{C}$.

allele of the major catalytic subunit gene $D C O$. This allowed us to investigate the effects of different levels of PKA activity on learning and memory using a Pavlovian olfactory learning assay. Animals with at least $50 \%$ of normal PKA activity throughout their development showed roughly normal learning and retention over $3 \mathrm{hr}$, whereas animals with $<25 \%$ of normal PKA activity throughout their development were defective in initial learning (Fig. 4A,B). After development was complete, further reduction of PKA activity (from 24\% to $16 \%$ ) did not produce any additional reduction in initial learning relative to controls assayed at the same temperature (Fig. 4C). However, a more rapid decay of memory was seen in animals with $16 \%$ of normal PKA activity relative to animals with $24 \%$ or $50 \%$ of normal PKA activity (Fig. 4C), when the temperature-shift-specific effects of the conditional allele were resolved. From these data we suggest an acute, physiological role for PKA in MTM.

\section{CHARACTERIZATION OF THE COLD-SENSITIVE MUTATIONS $D C O^{X 4}$ AND $D C O^{T 4}$}

We would ideally like to assay Drosophila learning in the complete absence of PKA activity.
A single gene, $D C O$, can account for all measurable PKA activity in homogenates of whole adult Drosophila (Lane and Kalderon 1993; this paper). However, this does not exclude the possibility that other catalytic subunits are expressed at low levels or in small groups of cells. We have recently shown that a second Drosopbila gene, DC2 (Kalderon and Rubin 1988), can behave as a PKA catalytic subunit in vitro (Melendez et al. 1995). Thus, null mutations in $D C O$ probably do not eliminate all PKA activity in Drosopbila. Furthermore, Drosopbila requires $D C O$ gene activity for oogenesis, embryogenesis, and survival past larval stages. We can therefore only test the effect of eliminating PKA on adult behavior by reducing PKA activity once development is complete or by limiting PKA dysfunction to specific cell types.

We have isolated two cold-sensitive $D C O$ alleles, $D C O^{T 4}$ and $D C O^{X 4}$, that provide enough PKA activity for apparently normal development at $25^{\circ} \mathrm{C}$ but that do not allow development beyond larval stages at $18^{\circ} \mathrm{C}$. Transferring adult $D C O^{T 4}$ or $D C O^{\mathrm{X}}$ hemizygotes raised at $25^{\circ} \mathrm{C}$ to $18^{\circ} \mathrm{C}$ did not affect their continued viability and allowed a behavioral analysis of learning in animals that have very low PKA activity.

Although the temperature-dependent change in PKA activity of $D C O^{X 4}$ hemizygotes is modest (from $24 \%$ to $16 \%$ of wild type), it appears to cross a threshold for several PKA-dependent processes. Mild defects in oogenesis of hemizygous $D C O^{X 4}$ adult females that are apparent at $25^{\circ} \mathrm{C}$ are markedly exaggerated at $18^{\circ} \mathrm{C}$ (M.E. Lane and D. Kalderon, unpubl.) and are accompanied by a reduction in egg laying (W. Li and D. Kalderon, unpubl.). Hemizygous $D C O^{X 4}$ larvae pupariate and eclose at $25^{\circ} \mathrm{C}$ but not at $18^{\circ} \mathrm{C}$. A variety of other $D C O$ allelic combinations also respect a threshold of $15 \%-20 \%$ of wild-type PKA activity that is apparently required for larval viability and normal oogenesis.

The quantitative requirement for PKA in a given cellular process may depend on a number of factors including the change, if any, in cAMP concentration to which it responds, the affinity of PKA for the relevant substrates, the concentration of substrate, and the activity of antagonistic phosphatases. Other studies have already provided empirical evidence for a threshold somewhere between $20 \%$ and $50 \%$ of wild-type PKA activity for normal initial learning (Skoulakis et al. 1993) and also for expression of circadian rhythms (Levine et al. 1994). We suspected that a second, lower

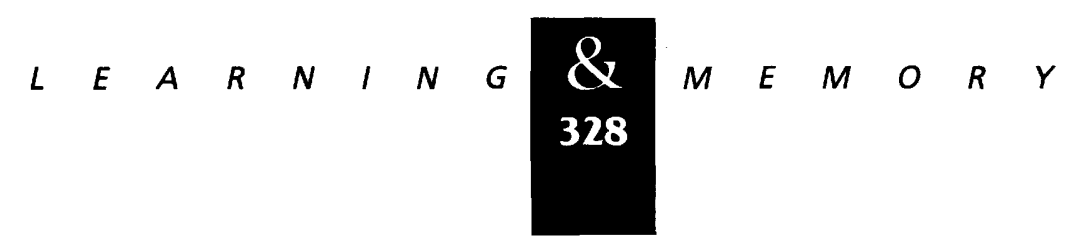


threshold, which we know to be critical for larval viability and oogenesis, might reveal a second distinct role of PKA in adult memory formation.

\section{BEHAVIORAL DEFECTS ASSOCIATED WITH REDUCTION OF PKA ACTIVITY}

The initial $25 \%$ learning deficit of $D C O^{X 4}$ hemizygotes relative to controls at $25^{\circ} \mathrm{C}$ in Pavlovian olfactory learning is most likely attributable to a reduction of PKA activity from $50 \%$ to $24 \%$. It is formally possible that other EMS-induced differences between the $D C O^{\mathrm{X}}{ }^{4}$ chromosome and its parent chromosome could have produced a dominant effect on learning behavior, but this is unlikely. A somewhat larger decrement in initial learning $(\sim 50 \%)$ was previously observed to result from an ostensibly similar change in PKA activity (Skoulakis et al. 1993). The quantitative difference in the learning defect seen in these two studies may reflect differences in the learning assays or, alternatively, in the nature of the PKA mutations used. The PKA biochemical assays measure the activity of PKA in whole adult or adult head extracts (with similar results) when maximally stimulated by cAMP rather than the activation state of PKA in vivo in the very cells that are responsible for associative learning. Hence, measurements that show similar reductions in PKA activity might mask important differences in the distribution, abundance, and specific activity of the kinase.

The substantial levels of initial learning of $D C O^{X 4}$ hemizygotes allowed us to monitor the time course of memory decay and also to examine the effects of a further reduction of PKA activity once development was complete. At $25^{\circ} \mathrm{C}$, memory decay in $D C O^{\mathrm{X}}{ }^{4}$ hemizygotes was very similar to that observed in wild-type flies. Previous learning assays had indicated that the performance of flies with altered PKA activity was very stable over a period of a few hours (Drain et al. 1991; Skoulakis et al. 1993). However, initial learning scores in those assays were low, possibly precluding a sensitive measurement of memory decay.

Shifting flies to $18^{\circ} \mathrm{C}$ prior to training reduced learning indices for all flies examined but showed some evidence of more rapid memory decay in $D C O^{\mathrm{X} 4}$ hemizygotes compared with controls. A three-way ANOVA did not reveal a temperatureshift-dependent effect of reducing PKA activity from $24 \%$ to $16 \%$ on memory decay among its interaction terms. Interaction terms in ANOVAs, however, possess low statistical power to detect even moderately large effects (Wahlsten 1990). We therefore devised a way to separate the temperature-shift-specific effects of the $D C O^{\mathrm{X} 4}$ mutation from the more general effects of genetic disruptions of $D C O$ or of temperature-dependent behavioral performance. We did this by calculating PI Ratios, which express mutant scores at each retention time as a proportion of their corresponding control scores. Then, we compared the memory curves for PI Ratios from different temperatures. This treatment of our data indicated that reducing PKA activity from $24 \%$ to $16 \%$ had no effect on initial learning but resulted in a transient memory deficit that was maximal $30 \mathrm{~min}$ after training and gone within 180 min after training (Fig. 4C).

The overall time course of the memory deficit appears similar to that ascribed previously to MTM, a form of memory that can be defined empirically by the use of "reversal" training procedures (Tully and Quinn 1985; Tully et al. 1990) and that appears to be absent from flies carrying mutations in the amn gene (Quinn et al. 1979; Tully et al. 1990). If we compare the memory curves of $a m n$ mutants at $25^{\circ} \mathrm{C}$ with those of $D C O^{X / 4}$ hemizygotes at $18^{\circ} \mathrm{C}$ using PI Ratios, we see almost identical curves (Fig. 6). If, as recently suggested (Feany and Quinn 1995), amn encodes a product that acts by raising intracellular cAMP concentration, we might expect to find a requirement for PKA in MTM formation, just as studies of $r u t$ and $d n c$ had implied a likely role for PKA in initial learning. In the future, our hypothesis that PKA is required for MTM may be tested more definitively by using a reversal training protocol on mutant $D C O^{\mathrm{X}}$ hemizygotes and controls or by assessing MTM in amn, $D C O^{X 4}$ double mutants.

\section{ROLE OF PKA IN DROSOPHILA LEARNING}

Many genetic studies testify directly or indirectly to the importance of PKA in Drosopbila learning and suggest that PKA is involved in a variety of memory phases. Mutations in $d n c$, a cAMP phosphodiesterase, rut, a calcium-dependent adenylyl cyclase, and PKA can each reduce learning at the earliest time measured but in no case reduce learning to zero (Tully and Quinn 1985; Dudai 1988; Han et al. 1992; Tully and Gold 1993; Dauwalder and Davis 1995). The amn gene may encode a precursor of several peptides including a homolog of mammalian pituitary adenylyl cyclaseactivating peptide (PACAP) (Feany and Quinn

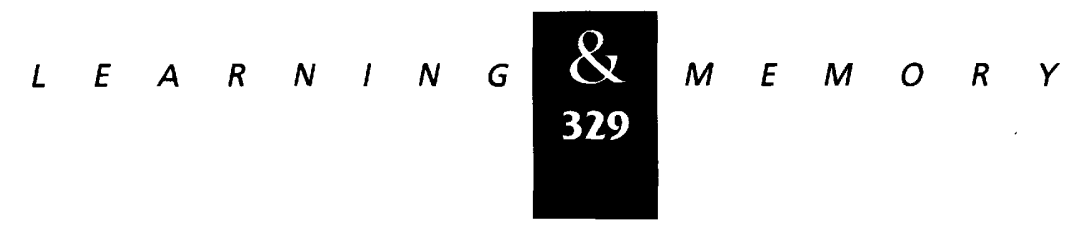


Li et al.

1995), so it may also act by modifying the state of PKA activation. amn mutations have little effect on initial learning but reduce retention of conditioned behavior measured at any time from 10 to $180 \mathrm{~min}$ following conditioning (Quinn et al. 1979; Tully et al. 1990; Tully and Gold 1993; Feany and Quinn 1995).

Longer-term memory can only be induced in normal flies by repeated training and can be separated into two components. The most durable memory, long-term memory (LTM), requires spaced training, is disrupted by inhibitors of protein synthesis, and may be eliminated or enhanced by manipulation of the activity of $d C R E B \cdot 2$ gene products (Tully et al. 1994; Yin et al. 1994, 1995). Mammalian homologs of $d C R E B-2$ encode transcription factors that change their activity in response to phosphorylation by PKA or calcium-dependent protein kinases (Gonzalez and Montminy 1989; Foulkes and Sassone-Corsi 1992; Sun et al. 1994). A second long-lasting form of memory is resistant to anesthesia and various other forms of disruption and, therefore, is termed ARM (anesthesia-resistant memory). ARM is disrupted by mutation of the radish gene (Folkers et al. 1993; Tully et al. 1994), but LTM is not. It is not known whether the radish gene product is involved in cAMP signal transduction.

For those aspects of learning and memory that appear to require normal cAMP signal transduction, we would like to define targets of signal transduction and investigate how alterations in their activity correlate with different memory phases. In particular, Is prolonged PKA activation necessary for any form of memory? and Do different memory phases depend on phosphorylation of different substrates by PKA? Presumably, during associative learning, neurotransmitter initially elevates cAMP levels and hence PKA activity via adenylyl cyclase, either through activation of a $G$ protein or elevation of calcium concentration. It is possible that PKA reverts to its initial activation state shortly thereafter as neurotransmitter is rapidly removed or degraded. However, activated PKA may be maintained for several minutes or hours, perhaps through continued presence of an activator of adenylyl cyclase, such as PACAP, or through proteolytic modification or degradation of regulatory subunit (Greenberg et al. 1987; Muller and Spatz 1989; Aszodi et al. 1991). In each case, the PKA signal could be extended further according to the decay rates of PKA substrates and other downstream effectors.
The use of more than one PKA substrate would allow for the generation of a variety of temporal memory phases from a single time-course of PKA activation. We have found that different PKA activities generate different memory curves, suggesting that there are indeed different threshold requirements for PKA in initial learning and memory. Changing PKA activity from $50 \%$ to $24 \%$ of wild type (throughout development) affected initial learning but not the subsequent time course of memory decay, whereas reducing PKA from $24 \%$ to $16 \%$ (in adults) was associated with more rapid memory decay without affecting initial learning. These observations are most easily accommodated by postulating that different PKA substrates are pertinent to the initial expression of learning and to memory. Clearly, the identification of the relevant PKA substrates and other effectors that selectively affect short- or medium-term memory would provide more definitive evidence in favor of this notion. Although the $D C O$ mutations we have used might be expected to affect PKA activity similarly in all cells, the precise numerical value of our PKA activity measurements in whole-fly extracts can only be taken as an approximation of the effects of mutations on PKA activity in the relevant subcellular microenvironment of those neurons pertinent to olfactory learning or memory storage.

Previous studies using single-gene mutants and different training protocols have suggested that longer-lasting memories (ARM and LTM) are, in part, dependent on the normal function of earlier memory phases (Tully et al. 1994). The use of a common biochemical component in several memory phases would provide a parsimonious explanation of this effect. It was assumed previously from the requirement for normal modulation of cAMP levels during acquisition and short-term memory (STM) and from the key role in LTM formation of the PKA substrate, CREB, that PKA activation was likely to be one such common component. Our use of a conditional PKA mutation to demonstrate separable roles for PKA in initial learning and in MTM provides further support for this hypothesis. In the future, it will be interesting to define how many distinct biochemical consequences relevant to learning and memory are initiated by PKA, whether these changes depend on additional signal transduction pathways, and whether the formation of different memory phases is restricted to specific cell types or subcellular compartments.

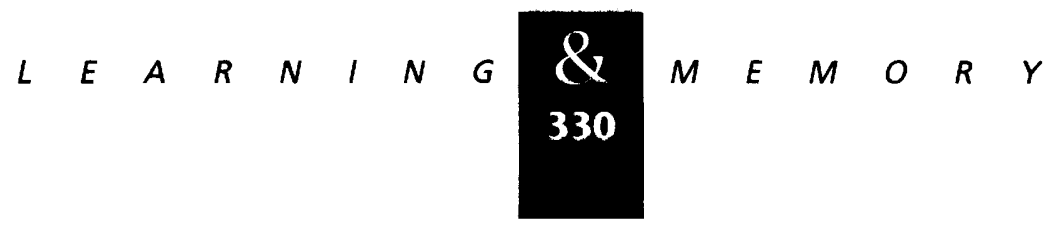




\section{Acknowledgments}

We thank Ralph Greenspan for advice on courtship conditioning assays that were used as a prelude to this work, Maria Del Vecchio for help with Pavlovian learning assays, and Ron Davis for discussions and comments on the manuscript. This work was supported by National Institutes of Health grant GM41815 and a Pew Scholars Award to D.K. The publication costs of this article were defrayed in part by payment of page charges. This article must therefore be hereby marked "advertisement" in accordance with 18 USC section 1734 solely to indicate this fact.

\section{References}

Alberini, C.M., M. Ghirardi, R. Metz, and E.R. Kandel. 1994. C/EBP is an immediate-early gene required for the consolidation of long-term facilitation in Aplysia. Cell 76: 1099-1114.

Aszodi, A., U. Muller, P. Friedrich, and H.-C. Spatz. 1991. Signal convergence on protein kinase $A$ as a molecular correlate of learning. Proc. Natl. Acad. Sci. 88: 5832-5836.

Bailey, C.H. and M. Chen. 1988. Long-term memory in Aplysia modulates the total number of varicosities of single identified sensory neurons. Proc. Natl. Acad. Sci. 85: 2373-2377.

Bellen, H.J., C.J. O'Kane, C. Wilson, U. Grossniklaus, R.K. Pearson, and W. Gehring. 1989. P-element-mediated enhancer detection: A versatile method to study development in Drosophila. Genes \& Dev. 3: 1288-1300.

Boynton, S. and T. Tully. 1992. latheo, a new gene involved in associative learning and memory in Drosophila melanogaster, identified from P-element mutagenesis. Genetics 131: 655-672.

Bradford, M.M. 1976. A rapid and sensitive method for the quantitation of microgram quantities of protein utilizing the principle of protein-dye binding. Anal. Biochem.

72: 655-672.

Byers, D., R.L. Davis, and J.A. Kiger. 1981. Defect in cAMP phosphodiesterase due to the dunce mutation of learning in Drosophila melanogaster. Nature 289: 79-81.

Coffino, P., H.R. Bourne, U. Freidrich, J. Hochman, P.A. Insel, I. Lemaire, K.L. Melmon, and G.M. Tomkins. 1976. Molecular mechanisms of cyclic AMP action: A genetic approach. Recent Prog. Horm. Res. 32: 669-684.

Cooper, D.M.F., N. Mons, and J.W. Karpen. 1995. Adenylyl cyclases and the interaction between calcium and CAMP signalling. Nature 374: 421-424.

Dash, P.K., K.A. Karl, M.A. Colicos, R. Prywes, and E.R. Kandel. 1991. cAMP response element binding protein is activated by $\mathrm{Ca}^{2+} /$ Calmodulin as well as cAMP-dependent protein kinase. Proc. Natl. Acad. Sci. 88: 5061-5065.

Dauwalder, B. and R.L. Davis. 1995. Conditional rescue of the dunce learning/memory and female fertility defects with Drosophila or rat transgenes. I. Neurosci. 15: 3490-3499.

Davis, R.L. 1993. Mushroom bodies and Drosophila learning. Neuron 11: 1-14.

Davis, R.L. and B. Dauwalder. 1991. The Drosophila dunce locus; learning and memory genes in the fly. Trends Genet. 7: 224-229.

deBelle, J.S. and M. Heisenberg. 1994. Associative odor learning in Drosophila abolished by chemical ablation of mushroom bodies. Science 263: 692-695.

Delgado, R., P. Hidalgo, F. Diaz, R. Latorre, and P. Labarca. 1991. A cyclic AMP-activated $\mathrm{K}^{+}$channel in Drosophila larval muscle is persistently activated in dunce. Proc. Natl. Acad. Sci. 88: 557-560.

Deutsch, P.J. and Y. Sun. 1992. The 38 amino-acid form of PACAP stimulates dual signalling cascades in PC12 cells and promotes neurite outgrowth. J. Biol. Chem. 267: 5108-5113.

Dhallan, R.S., K.-W. Yau, K.A. Schrader, and R.R. Reed. 1990. Primary structure and functional expression of a cyclic nucleotide-activated channel from olfactory neurons. Nature 347: 184-187.

Drain, P., E. Folkers, and W.G. Quinn. 1991. cAMP-dependent protein kinase and the disruption of learning in transgenic flies. Neuron 6: 71-82.

Dudai, Y. 1988. Neurogenetic dissection of learning and short-term memory in Drosophila. Annu. Rev. Neurosci. 11: $537-563$.

Dura, J.-M., T. Preat, and T. Tully. 1993. Identification of linotte, a new gene affecting learning and memory in Drosophila melanogaster. I. Neurogenet. 9: 1-14.

Feany, M.B. 1990. Rescue of the learning defect in dunce, a Drosophila learning mutant, by an allele of rutabaga, a second learning mutant. Proc. Natl. Acad. Sci. 87: 2795-2799.

Feany, M.B. and W.G. Quinn. 1995. A neuropeptide gene defined by the Drosophila memory mutant amnesiac. Science 268: 869-873.

Folkers, E., P. Drain, and W.G. Quinn. 1993. radish, a Drosophila mutant deficient in consolidated memory. Proc. Natl. Acad. Sci. 90: 8123-8127.

Foulkes, N.S. and P. Sassone-Corsi. 1992. More is better: Activators and repressors from the same gene. Cell 68: $411-414$.

Francis, S.H. and J.D. Corbin. 1994. Structure and function of cyclic nucleotide-dependent protein kinases. Annu. Rev. Physiol. 56: 237-272.

Geisler, N. and K. Weber. 1988. Phosphorylation of desmin in vitro inhibits formation of intermediate filaments;

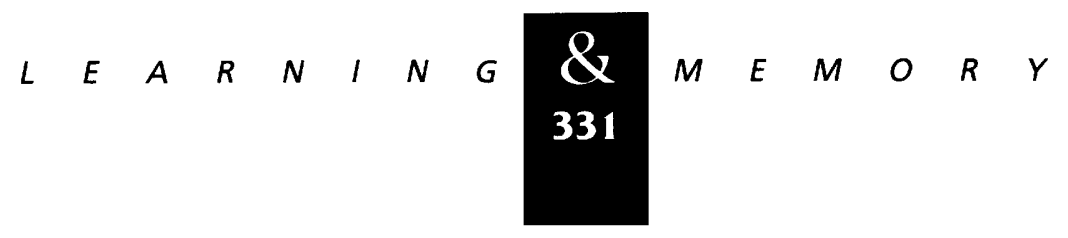


Li et al.

identification of three kinase $A$ sites in the amino terminal head domain. EMBO f. 7: 15-20.

Gilman, A.G. 1984. G proteins and dual control of adenylate cyclase. Cell 36: 577-579.

Gonzalez, G.A. and M.R. Montminy. 1989. Cyclic AMP stimulates somatostatin gene transcription by phosphorylation of CREB at serine 133. Cell 36: $577-579$.

Greenberg, S.M., V.F. Casstellucci, H. Bayley, and J.H. Schwartz. 1987. A molecular mechanism for long-term sensitization in Ap!ysia. Nature 329: 62-65.

Greengard, P., J. Jen, A.C. Nairn, and C.F. Stevens. 1991. Enhancement of the glutamate response by cAMP-dependent protein kinase in hippocampal neurons. Science 253: 1135-1138.

Griffith, L.C., L.M. Verselis, K.M. Aitken, C.P. Kyriacou, W. Danho, and R.J. Greenspan. 1993. Inhibition of Calcium/Calmodulin-dependent protein kinase in Drosophila disrupts behavioral plasticity. Neuron 10: 501-509.

Grigliatti, T. 1986. Mutagenesis in Drosophila, a practical approach. IRL Press, Oxford, UK.

Han, P.-L., L.R. Levin, R.R. Reed, and R.L. Davis. 1992. Preferred expression of the Drosophila rutabaga gene in mushroom bodies, neural centres for learning in insects. Neuron 9: 619-627.

Kaang, B.-K., E.R. Kandel, and S.G. Grant. 1993. Activation of cAMP-responsive genes by stimuli that produce long-term facilitation in Aplysia sensory neurons. Neuron 10: 427-435.

Kalderon, D. 1995. Responses to Hedgehog. Curr. Biol. 5: $580-582$.

Kalderon, D. and G.M. Rubin. 1988. Isolation and characterization of Drosophila cAMP-dependent protein kinase genes. Genes \& Dev. 2: 1539-1556.

Kandel, E.R. and J.H. Schwartz. 1982. Molecular biology of learning: Modulation of transmitter release. Science 218: $433-443$.

Lane, M.E. and D. Kalderon. 1993. Genetic investigation of cAMP-dependent protein kinase function in Drosophila development. Genes \& Dev. 7: 1229-1243.

1994. RNA localization along the anteroposterior axis of the Drosophila oocyte requires PKA-mediated signal transduction to direct normal microtubule organization. Genes \& Dev. 8: 2986-2995.

Levin, L.R., P.-L. Han, P.M. Huang, P.G. Feinstein, R.L. Davis, and R.R. Reed. 1992. The Drosophila learning and memory gene rutabaga encodes a

$\mathrm{Ca}^{2+} /$ calmodulin-responsive adenylyl cyclase. Cell 68: $479-489$.

Levine, J.D., C.I. Casey, D. Kalderon, and F.R. Jackson.
1994. Altered circadian pacemaker properties and cyclic AMP rhythms in Drosophila dunce mutants. Neuron 13: $967-974$.

Levitzki, A. 1988. From epinephrine to cyclic AMP. Science 241: 800-806.

Li, W. 1995. "Functions of Drosophila protein kinase A." Ph.D. thesis, Columbia University, New York, NY.

Livingstone, M.S., P.P. Sziber, and W.G. Quinn. 1984. Loss of calcium/calmodulin responsiveness in adenylate cyclase of rutabaga, a Drosophila learning mutant. Cell 37: 205-215.

Luo, L., T. Tully, and K. White. 1992. Human amyloid precursor protein ameliorates behavioral deficit of flies deleted for Appl gene. Neuron 9: 595-605.

Melendez, A., W. Li, and D. Kalderon. 1995. Activity, expression, and function of a second Drosophila PKA catalytic subunit gene. Genetics 141: 1507-1520.

Muller, U. and H.-C. Spatz. 1989. $\mathrm{Ca}^{2+}$-dependent proteolytic modification of the cAMP-dependent protein kinase in Drosophila wild-type and dunce memory mutants. J. Neurogenet. 6: 95-114.

Nakamura, T. and G.H. Gold. 1987. A cyclic nucleotide-gated conductance in olfactory receptor cilia. Nature 325: 442-444.

Quinn, W.G., P.P. Sziber, and R. Booker. 1979. The Drosophila memory mutant amnesiac. Nature 277: 212-214.

Raymond, L.R., C.D. Blackstone, and R.L. Hugaanir. 1993. Phosphorylation and modulation of recombinant GluR6 glutamate receptor by cAMP-dependent protein kinase. Nature 361: 637-641.

Rehfuss, R.P., K.W. Walton, M.M. Loriaux, and R.H. Goodman. 1991. The cAMP-regulated enhancer-binding protein ATF-1 activates transcription in response to cAMP-dependent protein kinase A. J. Biol. Chem. 266: 18431-18434.

Reinhard, M., M. Halbrugge, U. Scheer, C. Wiegand, B.M. Jockusch, and U. Walter. 1992. The $46 / 50 \mathrm{kDa}$ phosphoprotein VASP purified from human platelets is a novel protein associated with actin filaments and focal contacts. EMBO I. 11: 2063-2070.

Saudou, F., U. Boschert, J. Amlaiky, L. Plassat, and R. Hen. 1992. A family of Drosophila serotonin receptors with distinct intracellular signalling properties and expression patterns. EMBO /. 11: 7-17.

Scott, C.W., R.C. Spreen, I.L. Heerman, F.P. Chow, M.D. Davison, J. Young, and C.B. Caputo. 1993. Phosphorylation of recombinant Tau by cAMP-dependent protein kinase. J. Biol. Chem. 268: 1166-1173.

Siegel, R.W. and J.C. Hall. 1979. Conditioned responses in 
courtship behavior of normal and mutant Drosophila. Proc. Natl. Acad. Sci. 76: 3430-3434.

Skoulakis, E.M.C., D. Kalderon, and R.L. Davis. 1993. Preferential expression in the mushroom bodies of the catalytic subunit of protein kinase $A$ and its role in learning and memory. Neuron 11: 197-208.

Sokal, R.R. and F.J. Rohlf. 1981. Biometry. Freeman Press, New York, NY.

Sun, P., H. Enden, P.S. Myung, and R.A. Maurer. 1994. Differential activation of CREB by $\mathrm{Ca}^{2+} /$ calmodulin-dependent protein kinase type II and type IV involves phosphorylation of a site that negatively regulates activity. Genes \& Dev. 8: 2327-2339.

Sutherland, E.W. 1972. Studies on the mechanism of hormone action. Science 177: 401-408.

Swope, S.L., S.J. Moss, C.D. Blackstone, and R.L. Huganir. 1992. Phosphorylation of ligand-gated ion channels: A possible mode of synaptic plasticity. FASEB I. 6: 2514-2523.

Tatsuno, I., T. Yada, S. Vigh, H. Hidaka, and A. Arimura. 1992. Pituitary adenylyl cyclase activating polypeptide and vaso-active intestinal peptide increase cytosolic free calcium concentration in cultured rat hippocampal cells.

Endocrinology 131: 73-81.

Toda, T., S. Cameron, P. Sass, M. Zoller, and M. Wigler. 1987. Three different genes in S. cerevisiae encode the catalytic subunits of the CAMP-dependent protein kinase. Cell 50: $277-287$.

Tully, T. 1991. Genetic dissection of learning and memory in Drosophila melanogaster. In Neurobiology of learning, emotion and affect (ed. J. Madden), pp. 29-66. Raven Press. New York, NY.

Tully, T. and J. Hirsch. 1982. Behavior-genetic analysis of Phormia regina: II. Detection of a single major-gene effect from behavioural variation for the central excitatory state (CES) using replicate hybrid crosses. Anim. Behav. 30: 1193-1202.

Tully, T. and W.G. Quinn. 1985. Classical conditioning and retention in normal and mutant Drosophila melanogaster. I. Comp. Physiol. A157: 263-277.

Tully, T. and D. Gold. 1993. Differential effects of dunce mutations on associative learning and memory in Drosophila. I. Neurogenet. 9: 55-71.

Tully, T., S. Boynton, C. Brandes, J.-M. Dura, R. Mihalek, T. Preat, and A. Villella. 1990. Genetic dissection of memory formation in Drosophila melanogaster. Cold Spring Harbor Symp. Quant. Biol. 55: 203-211.

Tully, T., T. Preat, S.C. Boynton, and M. Del Vecchio. 1994. Genetic dissection of consolidated memory in Drosophila. Cell 79: 35-47.
Uzzan, A. and Y. Dudai. 1982. Aminergic receptors in Drosophila melanogaster: Responsiveness of adenylate cyclase to putative neurotransmitters. J. Neurochem. 38: 1542-1550.

Wahlsten, D. 1990. Insensitivity of the analysis of variance to heredity-environment interaction. Behav. Brain Res. 13: 109-161.

Walaas, S.I. and P. Greengard. 1991. Protein phosphorylation and neuronal function. Pharmacol. Rev. 43: 299-349.

Wang, L.-Y., F.A. Taverna, X.-P. Huang, J.F. MacDonald, and D.R. Hampson. 1993. Phosphorylation and modulation of a Kainate receptor (GluR6) by cAMP-dependent protein kinase. Science 259: 1173-1175.

Yin, J.C.P., J.D. Wallach, M.D. Vecchio, E.L. Wilder, H. Zhou, W.G. Quinn, and T. Tully. 1994. Induction of a dominant negative CREB transgene specifically blocks long-term memory in Drosophila. Cell 79: 49-58.

Yin, J.C.P., M.D. Vecchio, H. Zhou, and T. Tully. 1995. CREB as a memory modulator: Induced expression of a dCREB2 isoform enhances long-term memory in Drosophila. Cell 81: 107-115.

Received lanuary 5, 1996; accepted in revised form March 25, 1996.

$$
\begin{array}{llllllllllllllll}
\hline & E & A & R & N & I & N & G & \begin{array}{l}
\boldsymbol{Q} \\
333
\end{array} & M & E & M & O & R & Y
\end{array}
$$




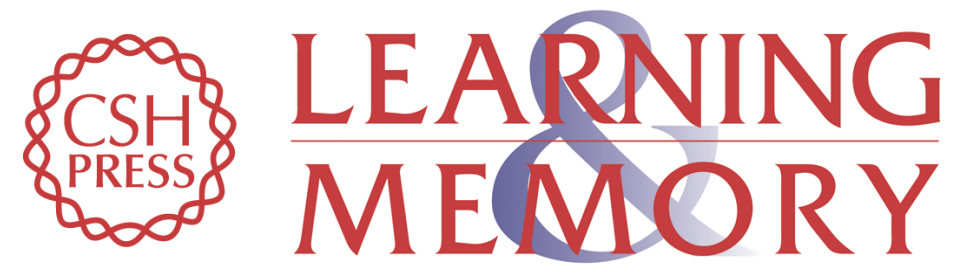

\section{Effects of a conditional Drosophila PKA mutant on olfactory learning and memory.}

W Li, T Tully and D Kalderon

Learn. Mem. 1996, 2:

Access the most recent version at doi:10.1101//m.2.6.320

References This article cites 70 articles, 26 of which can be accessed free at: http://learnmem.cshlp.org/content/2/6/320.full.html\#ref-list-1

License

Email Alerting Receive free email alerts when new articles cite this article - sign up in the box at the Service top right corner of the article or click here. 